\section{Beneficência e paternalismo médico}

\section{Beneficence and medical paternalism}

Henrique Batista e Silva 1

\footnotetext{
1 Programa de Doutoramento em Bioética. Faculdade de Medicina. Universidade do Porto. Alameda Prof. Hernâni Monteiro, 4200319. Porto, Portugal. E-mail: henriqba@portalmedico.org.br
}

\begin{abstract}
The author addresses the relevant issue of the relationship between doctor and patient, considering that biomedical research applications could raise dilemmas to the medical profession's practice in a contemporary and secular society. In this context, he seeks to discuss the medical attendance and analyses aspects concerned with paternalism and the prerogatives of patient's autonomy in perspective of the beneficence and autonomy principles.

The beneficence constitutes one of the prerogatives in Medicine practice and relates to acting in the patient's best interest; beneficence takes on a character of bioethics reflection, and the application of the rules implies distinguishing general beneficence from specific beneficence; making medical decision without considering the opinion from a fully capable patient constitutes an unilateral conduct, called medical paternalism; paternalism can be ethically justified, and sometimes necessary, when there is a temporary or permanent limitation of the patient's self-determination; it is necessary to understand that the application of beneficence actions on a medical attendance takes place within a doctor/patient relationship. The better this relationship is built up, the better the doctor's decision will be in not causing damage to the patient until the procedures of acting for his benefit, respecting his autonomy. We believe that beneficence and paternalism would be more compatible in a relationship where the doctor kept his authority, preserving his knowledge and taking responsibility for making decision, and the patient, in turn, would also take part according to his moral and personal values.
\end{abstract}

Key words Paternalism, Personal autonomy, Beneficence

\section{Resumo}

$O$ autor discute a relação médico-paciente, considerando que na sociedade contemporânea e secularizada as aplicações decorrentes das pesquisas biomédicas trazem dilemas ao exercício profissional. Discorre sobre o atendimento, analisando o paternalismo e a autonomia do paciente na perspectiva dos princípios da beneficência e da autonomia.

A beneficência se constitui em uma das prerrogativas do exercício da Medicina dizendo respeito a agir no melhor interesse do paciente. Para a reflexão bioética sua aplicação importa em distinguir a beneficência geral da específica quando da tomada de decisão médica. Desconsiderar a opinião do paciente plenamente capaz constitui conduta unilateral, o paternalismo médico, que pode ser eticamente justificado, e por vezes necessário, apenas quando existe limitação na autodeterminação do paciente, momentânea ou definitiva. Torna-se necessário, portanto, entender que as ações beneficentes no atendimento clínico são inerentes à relação médicopaciente e quanto melhor essa relação é construida, tanto melhor será a decisão médica, que não cause dano ao paciente e possa agir em seu benefício, respeitando sua autonomia. Para compatibilizar beneficência e paternalismo o médico precisa manter sua autoridade, preservando seus conhecimentos e responsabilizando-se pela tomada da decisão, e o paciente participar do processo de escolha de acordo com seus valores morais e pessoais.

Palavras-chave Paternalismo, Autonomia pessoal, Beneficência 


\section{Introdução}

Emergem das fronteiras das pesquisas biomédicas possibilidades de novos conhecimentos, cujas aplicações podem trazer também vários impasses e dilemas capazes de promover questionamentos e discussões no âmbito da bioética.

$\mathrm{O}$ exercício da medicina no final do século XX, com seu portentoso desenvolvimento científico e tecnológico, transita com muitas questões emergentes, como a utilização de células tronco em doenças degenerativas, a descriminalização do aborto, a clonagem humana, a mercantilização do corpo, a questão do consentimento informado, livre e esclarecido do sujeito e, a pesquisa científica utilizando seres humanos. Também antigos temas, que estão sempre atualizados pela sua importância social, como o pertinente à concepção deontológica como regra do comportamento humano, o uso do utilitarismo justificado, a procriação como livre escolha, a esterilização coagida e induzida, o conflito entre a destinação de medicamentos para pacientes especiais e as decisões coletivas no âmbito da saúde pública. Agregam-se a esses temas a questão da ética dos políticos e nas instituições empresariais. São tão vastos e complexos os problemas na vida cotidiana que cada vez mais se torna necessário que profissionais de várias áreas do conhecimento humano se disponham a refletir sobre esses problemas, diante dos quais parece difícil estabelecer a formação de um senso comum.

O exercício do comportamento ético, presente nos vários campos do conhecimento se encontra especialmente evidenciado no atendimento médico, quando se refere à interface entre a beneficência e a autonomia do paciente. Assunto de conteúdo bioético que se estabelece quando o médico, pela sua vontade e autonomia profissional, exerce seu ofício ao fazer o melhor para o paciente, agindo de forma a acordar ou não respeitar a autonomia do paciente.

Sem dúvida que os médicos sempre se comportaram com as prerrogativas de conduzir suas decisões baseadas nos conhecimentos científicos da medicina, fundamentado no princípio do agir sempre em beneficio do paciente. Nesse aspecto, ressaltamos o princípio da beneficência e da não maleficência, evidenciado nos aforismos hipocráticos: primum no nocere e, ajudar sempre. Entretanto, essa primazia do profissional médico está sendo questionada no âmbito da autonomia do paciente, marcada pela emergência dos movimentos de reivindicação dos direitos humanos, considerando-se que o médico não possui total autoridade sobre o paciente. Concepção consolidada a partir da introdução do termo bioética pelo cancerologista Van Potter na década de $1970^{1}$ e estabelecidos na corrente do principialismo, ${ }^{2}$ abordagem que se tornou clássica ao estabelecer os princípios que buscam elucidar e encontrar a solução dos dilemas éticos na saúde: justiça, autonomia, beneficência e não-maleficência.

Nesse contexto, o objetivo deste trabalho é fazer uma reflexão sobre as pertinências bioéticas da relação médico-paciente, buscando entender as decisões médicas, considerando o dever profissional do médico e o respeito à autonomia do paciente. Cabe, então, desenvolver uma análise dos principais conceitos que norteiam a questão e os vários questionamentos implicados na beneficência e no paternalismo médico.

\section{Fundamentação}

Ao construir nossa reflexão sobre o tema, beneficência e paternalismo médico, devemos inicialmente considerar que a compreensão do processo de tomada de decisão é um elemento fundamental na bioética que envolve o princípio da beneficência e o paternalismo médico.

No âmbito das políticas de saúde, deve-se atentar para o princípio da justiça e o da utilidade na distribuição de benefícios, riscos e custos. São princípios que ponderam a decisão mais apropriada para as ações públicas de saúde, mas que precisam ser restringidos por normas morais, como o princípio da justiça, da beneficência e da não-maleficência. Ao enfocar especificamente as considerações sobre a beneficência e o paternalismo, entendemos que a aplicação das ações beneficentes no atendimento clínico se processa dentro da relação médicopaciente. Ressaltamos que tanto quanto melhor essa relação é construída, tanto melhor será a decisão médica que vai de não causar dano à propiciar benefícios.

Goldim e Francisconi ${ }^{3}$ em 2000 expuseram os modelos de relação médico-paciente, baseados na proposta de Robert Veatch, do Instituto Kennedy de Ética da Universidade Georgetown/EEUU, em 1972, que seriam os modelos: sacerdotal, engenheiro, colegial e contratualista.

O modelo sacerdotal, baseado na tradição hipocrática, assume uma postura paternalista com relação ao paciente que em nome da beneficência a decisão tomada pelo médico não considera a vontade do paciente. Dessa maneira, o processo de tomada de decisão é de baixo envolvimento, baseando-se em uma relação de dominação por parte do médico e de submissão por parte do paciente. Explicam que em 
função deste modelo o termo 'paciente' - palavra de origem grega, significando aquele que sofre - passou a ser utilizado com conotação de passividade.

No modelo engenheiro o poder de decisão pertence ao paciente. O médico prestaria as informações e o paciente assumiria a poder de decisão. É também um modelo de tomada de decisão de baixo envolvimento, em que o médico se colocaria numa posição de acomodação e haveria a dominação por parte do paciente.

Por outro lado, os modelos de alto envolvimento seriam o colegial e o contratualista. No modelo colegial a tomada de decisão é tomada de forma igualitária, compartilhada pelo médico e pelo paciente, não prevalecendo o poder da autoridade do médico, respeitando o direito do paciente. Ressalta-se que existe uma restrição a este modelo que é uma relação entre indivíduos iguais, onde se restringe a função preponderante do médico na relação médicopaciente.

No modelo contratualista, o médico manteria sua autoridade, preservando seus conhecimentos e se responsabilizando pela tomada da decisão. $\mathrm{O}$ paciente, por sua vez, também participaria, fazendo valer suas crenças e desejos, de acordo com seus valores morais e pessoais. O processo de tomada de decisão seria objeto de uma verdadeira troca de informações e a tomada de decisão poderia ser de médio ou alto envolvimento, dependendo do compromisso estabelecido entre o médico e o paciente. A Tabela 1 conforme Goldim e Francisconi ${ }^{3}$ estabelece as principais características dos modelos de relação médico-paciente.

Em 1992, foi apresentada outra proposta para esses modelos. ${ }^{4}$ De acordo com essa proposta, o modelo sacerdotal seria denominado de paternalístico e o modelo do engenheiro seria chamado de informativo. Sem se referir ao modelo colegial, subdividem o modelo contratualista em dois outros, interpretativo (médio envolvimento) e deliberativo (alto envolvimento), considerando o grau de autonomia do paciente. Ainda comentam a possibilidade da existência de um quinto modelo que seria chamado de instrumental, onde o paciente seria utilizado pelo médico apenas como um meio para atingir outra finalidade, citando como exemplo a utilização abusiva de pacientes em projetos de pesquisa, tal como o realizado em Tuskegee.

Neste contexto, nos quatro modelos de relação médico-paciente, ressaltam-se os princípios da beneficência e o paternalismo médico.

$\mathrm{O}$ princípio do respeito à vida constitui o princípio mais invocado na sociedade ocidental como o fulcro das normas morais, das regras do direito, das políticas sociais e dos direitos humanos. Ele tem origem na proibição de matar apenas às pessoas do clã, uma exigência da sobrevivência clânica. Gradativamente o preceito alcançou toda a humanidade. O não matarás continha uma clara afirmação em favor da proteção e da promoção da vida humana. Entendeu-se que ele não somente proibia que não se matasse, mas que também não se praticasse o mal às outras pessoas, admitindo, contudo, exceções: legítima defesa, pena de morte, guerra justa. $\mathrm{O}$ respeito à vida interessa sobremaneira ao médico, guardião da vida por princípio. Designa globalmente a exigência de respeito, de proteção e de promoção da vida humana, sob todas as circuns-

Tabela 1

Modelos de relação médico-paciente.

\begin{tabular}{|c|c|c|c|c|}
\hline Modelo & Autoridade & Poder & $\begin{array}{l}\text { Relação de poder } \\
\text { do médico }\end{array}$ & $\begin{array}{c}\text { Relação de poder } \\
\text { do paciente }\end{array}$ \\
\hline Sacerdotal & médico & médico & dominação & submissão \\
\hline Engenheiro & médico & paciente & acomodação & variável \\
\hline Colegial & - & igualitário & negociação & negociação \\
\hline Contratualista & médico & compartilhado & compromisso & compromisso \\
\hline
\end{tabular}

Fonte: Goldim e Francisconi. 3 
tâncias, em si mesmo e nos outros seres humanos. A vida humana deve ser protegida e defendida com um cuidado especial e extremo. Seja no sentido de vitalismo, subentendendo-se biológica (valor absoluto) ou com a interpretação humanista, em que a vida biológica não é mais um valor absoluto, mas, sobretudo a preocupação com a saúde, o bem estar, a qualidade de vida, a promoção de todas as capacidades da pessoa; é o suporte da vida pessoal. Nesse raciocínio, incluindo a promoção da qualidade de vida, suscita a questão da beneficência. ${ }^{1}$

A beneficência, etimologicamente, bene-facere, significa fazer o bem. Importa distingui-la da benevolência que se refere ao traço de caráter ou à virtude ligada à disposição de agir com bondade. Como na ética não é suficiente fazer o bem, é preciso também se preocupar com o outro e, compartilhar do seu sofrimento, isso introduz a noção de benevolência, termo que evoca o cuidado fraterno. A beneficência não seria caritativa, ou da ordem da bondade, mas do dever.

A beneficência é um princípio retomado pelo direito e pela deontologia, com exigências maiores ou menores, e é uma das exigências das profissões de saúde; significa aplicar os recursos da medicina para curar, aliviar os sofrimentos, melhorar o bemestar. É ao mesmo tempo, um dever, uma virtude, um princípio, um valor. A palavra dever designando diretamente a obrigação moral ou a norma; a virtude, relativo a uma atitude interior; o princípio, a inspiração e legitimação; o valor, um objetivo a ser alcançado. Disso se depreende seu significado para a medicina que é um princípio ressaltado e buscado como o maior valor para o exercício profissional, isto é, toda a ação do médico visa o bem do ser humano.

As regras da beneficência não representam modos rígidos de ação, nem sempre são exigências obrigatórias e imparciais e que, portanto, precisam ser obedecidas. Não é esse, entretanto, o entendimento dos que advogam a beneficência geral e obrigatória, os utilitaristas e os moralistas cristãos.5,6 Sustentam que a beneficência deve ser geral, obrigatória e inespecífica, devendo beneficiar todas as pessoas indistintamente. Diferentemente dos que entendem desta forma, a beneficência específica, em que podemos beneficiar às pessoas com quem temos convivência, mas não somos exigidos moralmente que ajudemos àqueles que não tenhamos um relacionamento especial; não seria admissível agir de modo beneficente para todos, porque não se pode exigir o impossível. Há de se compreender que é improvável ou mesmo perigoso, que se possa praticar ações beneficentes de maneira generalizada, abrangendo aqueles que estão fora do círculo das pessoas que nos são próximas, como ocorre nas relações de parentesco e amizade, frente às quais nos sentimos compelidos à ação beneficente, muitas vezes até o ponto de perder os limites da realidade. Nas situações em que se poderia exigir que a beneficência fosse geral e obrigatória deve-se considerar, ademais, os limites impostos pela própria exiguidade de recursos, que impedem que se possa efetivamente de atender a todos em todas as circunstâncias.

O princípio da beneficência específica se caracteriza por uma série de regras morais que são: a) proteger e defender os direitos dos outros; b) evitar que outros sofram; c) eliminar as condições que causarão danos a outros; d) ajudar pessoas inaptas; e) socorrer pessoas que estão em perigo. ${ }^{2}$

Também podemos distinguir as regras da beneficência das regras da não-maleficência ${ }^{2}$ porque estas representam proibições peremptórias e que podem servir para formular modos de agir. Não provocar, ou não contribuir para o que entendemos moralmente como mal, é sempre possível. Assim, somos obrigados a agir de modo a não provocar danos aos outros ou a nós mesmos. Para todos, devemos agir sempre sob o principio da nãomaleficência, ou seja, não devemos infligir males ou danos. São obrigações mais diretas e mais rigorosas do que as regras da beneficência. A não-maleficência detém uma formulação e requer apenas que não pratiquemos ações ou atos que causem danos.

A beneficência exige um comportamento ativo, positivo, de impedir que ocorram males, sanar danos e promover o bem, dentro do entendimento acima exposto, ou seja, da beneficência específica que atende as relações morais especiais. Também importa a idéia de que a beneficência pertence aos cuidados médicos e a assistência à saúde, fundamentada nos princípios hipocráticos. Historicamente, cabia ao médico a incumbência de cuidar do paciente, de acordo com sua autonomia, baseada nos seus conhecimento científico. Ao longo da evolução do conhecimento científico sempre foi conferido à medicina, os princípios da beneficência e da nãomaleficência como justificativa paternalista dispensada aos pacientes. Essa idéia foi reforçada a partir da segunda metade do século XIX, quando importantes descobertas possibilitaram extraordinário progresso, reforçando a autonomia médica. Esses parâmetros científicos conferiram maior poder de intervenção médica sobre o paciente, substituindo uma boa relação médico-paciente pela prática de solicitação e execução de exames, e por medicamentos mais eficazes. ${ }^{7}$ Contudo, apesar da compe- 
tência tecnocientífica, com a incorporação dos direitos dos pacientes nos últimos trinta anos surgiu a preocupação com essa prerrogativa médica, o paternalismo.

O paternalismo se refere ao dilema bioético, se o respeito à autonomia do paciente cabe restrição à autonomia do médico de exercer sua autoridade profissional. De modo mais simples, paternalismo significa o governo paternal, em que o pai se responsabiliza em prover seus dependentes, com total autoridade, restringindo suas liberdades. O paternalismo se constitui na forma de exercer ação, objetivando beneficiar a pessoa, cuja vontade ou interesses deixam de ser respeitados.

Existem duas posições em favor do respeito ao paciente, que provém do fato de que cabe ao médico promover os meios necessários ao diagnóstico e ao tratamento do paciente, mas que não deve assumir uma postura solitária e autoritária. ${ }^{8}$ Para outros, o médico deve obrigações de compartilhar as informações, de revelar os diagnósticos, de buscar o consentimento do paciente, além de manter o sigilo e de respeitar sua privacidade, sem deixar de executar sua ação de prover os benefícios. ${ }^{8}$

Apesar de pensadores, como Kant, considerarem injustificável o governo paternalista em que se restringiam as liberdades das pessoas, o certo é que atualmente a medicina, muitas vezes, patrocina a intervenção na vida das pessoas de modo paternalístico, sem considerar o respeito ao paciente. ${ }^{2}$

Torna-se importante, para melhor elucidação da questão do paternalismo médico, distinguir duas formas de comportamento paternalista: o paternalismo fraco e o paternalismo forte. 8

No caso do paternalismo fraco, o médico pode deixar de informar ao paciente determinada ação, se houver uma habilidade comprometida ou enfraquecida, que lhe possibilitasse, de posse dessa informação, tomar uma decisão capaz de lhe provocar algum dano. Um exemplo seria o caso de uma senhora com câncer de mama, mas que também sofrendo de uma síndrome depressiva muito intensa, com passado de tentativas de suicídio. A possibilidade de que possa vir a cometer suicídio por conta de o médico lhe informar o diagnostico, pode-se justificar uma conduta paternalista. Desse tipo de paternalismo fraco ou justificado, nem mesmo os antipaternalistas ousam discordar. Pode-se, até discutir se esse tipo de paternalismo fraco, deveria ser considerado como paternalismo. Não necessita de defesa, pois os possíveis danos ou inconvenientes suplantam a perda parcial da autonomia do paciente, ou ainda, entendendo que o paciente fosse consentir, caso estivesse em pleno uso das suas capacidades decisórias. Exemplo seria o caso de um doente mental, sem condições de receber alta hospitalar, apesar de conduta responsável no hospício, mas que se sabe que quando recebe alta se automutila.

Suscita-se, também, no paternalismo fraco, a noção do consentimento do paciente que justificaria e delimitaria o campo de sua ação. Esse consentimento poderia ser de forma posterior ou um consentimento hipotético. Em outras palavras, as pessoas poderiam estar incapacitadas para compreender suficientemente os riscos a que estariam submetidas e outros com maiores conhecimentos e habilidades assumiriam o processo decisório, no caso em consideração, o profissional da medicina. ${ }^{8}$

No paternalismo forte perpassam decisões fortes e unilaterais e, como podem ser abusivas, devem ser questionadas no campo da saúde. Necessário, entretanto, considerar que certos atos de paternalismo podem ser justificados em um leque limitado de situações. ${ }^{8}$ Situações exemplificadas em alguns casos que dão margens para reflexão da necessidade de paternalismo médico. Um deles se refere ao de um paciente, idoso, ansioso, com quadro doloroso precordial recente, cujo resultado do teste ergométrico foi altamente compatível com isquemia miocárdica. O paciente demonstra receio de doença coronariana, por medo de possível intervenção cirúrgica. Nesse caso, o médico omite o resultado inicial e solicita cateterismo cardíaco, para através do exame coronariográfico, confirmar comprometimento arterial. Somente depois do resultado, esclarecer ao paciente, a necessidade imediata de intervenção cirúrgica, em razão de grave lesão, comprometendo o tronco da artéria coronária esquerda. Considerando que o médico conhece o paciente há muito tempo, havendo a possibilidade do paciente se ausentar ao tomar conhecimento do primeiro exame cardiológico, e ainda, em razão do seu estado de ansiedade, tomar uma decisão precipitada e danosa, julgamos que se pode aceitar a atitude paternalista do médico. Atitude de colocar acima da omissão inicial, a intenção de buscar o benefício do paciente, a cirurgia sendo realizada, com resultados a contento, deixando o paciente assintomático e, portanto, fora do risco de morte súbita.

Outro caso refere-se ao de um paciente internado que recebe medicação pré-anestésica, e ainda, consciente, antes dos efeitos da medicação, recusase a ser contido na maca, alegando a não necessidade dessa contensão, por se encontrar lúcido. Entretanto, a contensão é realizada, justificada pelos efeitos de sedação que logo ocorrerá, pela falta de pessoal suficiente na ala para cuidar do paciente e a possibilidade real do paciente cair da maca e sofrer danos. 
Os casos envolvendo convicção religiosa, como o das Testemunhas de Jeová que se recusam a receber transfusão sanguínea têm dado margem a grandes debates e são exemplos de dilemas éticos. A legislação brasileira prevê a possibilidade de o médico intervir se houver risco de dano, como quadro de choque hipovolêmico e risco de morte iminente. Nesse caso, existe um interesse maior de preservar a vida do paciente, mesmo contra a sua opinião. É um paternalismo justificado. Entretanto, se o médico persuadir o paciente da necessidade terapêutica, estaríamos diante do respeito ao paciente, e assim, deixaria de ser exemplo de paternalismo. Ou quando o médico usa expansores do plasma, substituindo o sangue, também respeitando a vontade do paciente.

Nesse contexto, julgamos que o paternalismo forte pode ser considerado justificado ou apropriado quando satisfeitas algumas condições: quando o paciente estiver exposto a um risco grave, e a ação paternalista possa evitar o dano, ou ainda, quando os benefícios advindos da ação médica, suplantarem os inconvenientes e o desrespeito à autonomia do paciente.

Há de se considerar os casos que se referem à solicitação do paciente ou de seus responsáveis por exames ou tratamentos considerados inoportunos ou não-benéfícos e o médico se recusa a atendê-los. Um paciente jovem e assintomático solicita do médico a realização de uma punção medular porque receia a existência de leucemia. Seria o caso de uma forma de paternalismo, justificado, passivo, negando uma vontade do paciente, considerando que não há justificativa clínica e existe a possibilidade de complicações decorrentes do procedimento. No que se refere ao debate da futilidade médica, se os recursos de suporte da vida, são fúteis, então estão justificados os atos de paternalismo médico ao negar as solicitações de tratamento. ${ }^{8}$

Há quatro anos o Conselho Federal de Medicina aprovou a Resolução $\mathrm{n}^{\circ} 1.805 / 2006^{9}$ que regulamenta a possibilidade de o médico limitar ou suspender procedimentos ou tratamentos que prolonguem a vida do doente em fase terminal de enfermidades graves e incuráveis. No nosso entendimento, trata-se de paternalismo justificado, vez que confirmada situação irreversível e incurável do paciente, não existem razões médicas para continuar com procedimentos heróicos e fúteis, que podem contribuir para sofrimento do paciente. A continuação desse tratamento fútil seria distanásia ao passo que sua suspensão constituiria ortotanásia.

A citada resolução ${ }^{9}$ permaneceu sob justice até recentemente, com efeitos suspensos por decisão judicial em ação ajuizada pelo Ministério Público Federal, 10 quando recebeu sentença favorável, por considerar o juiz que "realmente não ofende o ordenamento jurídico posto". ${ }^{11}$ Como se vê, a questão da futilidade médica é delicada, mas tanto no entendimento da classe médica quanto na compreensão do poder judiciário essa complexa questão parece estarse elucidando, conforme o pressuposto no rol dos direitos e garantias fundamentais, consolidados na Constituição Brasileira de 1988.12

São condições básicas para aplicar a chamada futilidade médica: o procedimento não pode ser realizado em decorrência de uma impossibilidade biológica; o tratamento pode não produzir o beneficio esperado; não se tem certeza de se alcançar tratamento eficaz. No caso de se compatibilizar os benefícios com custo e ônus não tem relação com a questão da futilidade. 2

Ainda podemos nos referir que a alegação do médico de que o procedimento é fútil - por exemplo, o prolongamento da vida de um paciente terminal com respiradores mecânicos por alguns dias - pode representar grande importância para os familiares por razões sentimentais. Nesse caso, a decisão extrapola o julgamento médico e sua ação paternalista se torna indesculpável.

Ao término dessas considerações sobre tema tão vasto e complexo, entendemos que paternalismo quando restringe totalmente as ações e os interesses do paciente, tende para o paternalismo forte. Como exemplo, temos o caso de doente mental, cuja ação se justifica se existe possibilidade de causar dano em si mesmo ou em outras pessoas. Também nos casos de pacientes muito deprimidos ou drogados que têm pouca possibilidade de escolher a melhor decisão, ou ainda, embora capazes, podem fazer escolhas prejudiciais ao seu tratamento, o médico poderá agir de forma beneficente, apesar de que outros médicos ajam de forma a respeitar a decisão do paciente, mesmo tentando convencê-lo com explicações baseadas no conhecimento científico. Por outro lado, à medida que a ação médica pende para a autonomia do paciente, pode-se entender como paternalismo fraco. Nesse caso, também respeitando os benefícios do procedimento diagnóstico ou terapêutico.

\section{Considerações finais}

a) A beneficência se constitui em uma das prerrogativas do exercício da medicina e diz respeito a agir no melhor interesse do paciente; deve ser diferenciada da benevolência que se caracteriza por ações benéficas, de cunho caritativas e que alguns ainda a identificam como vocação sacerdotal do trabalho 
médico;

b) A beneficência assume um caráter de reflexão bioética quando adquire características de prestação de benefícios ao paciente, considerando algumas regras de aplicação, respeitando a autonomia do paciente;

c) A aplicação das regras importa em distinguir a beneficência geral e obrigatória da beneficência especifica. Aquela prega ação generalizada, entendendo que se deve buscar o bem de todas as pessoas, de modo indistinto. A beneficência especifica suscita um comportamento positivo, impedindo que ocorram males, sanando danos e promovendo o bem, mas atendendo limites nas relações morais especiais e na assistência à saúde;

d) Quando a tomada de decisão médica desconsidera a opinião do paciente plenamente capaz, ou quando o médico se deixa influenciar por pressões familiares ou institucionais, constitui-se em uma conduta unilateral, chamada de paternalismo médico;

e) O paternalismo pode ser eticamente justificado, e por vezes necessário, quando existe uma limitação

\section{Referências}

1. Durant G. Introdução geral à bioética. São Paulo: Loyola 2003

2. Beauchamp TL, Childress JF. Princípios de ética biomédica. São Paulo: Loyola; 2002.

3. Goldim JR, Francisconi CF. Modelos de relação médicopaciente. 2000. [on line] Disponível em: www.ufrgs.br/ bioetica/modelos/htm

4. Emanuel E, Emanuel L. Four models of the physicianpatient relationship. JAMA. 1992; 267: 2221-6.

5. Bentham J. An introduction to the principles of moral and legislation. Oxford: Clarendon Press; 1970. p.11-4; 31-4.

6. Ross WD. The right and the good. Oxford: Clarendon Press; 1930. p. 19-36.

7. Nascimento PG, Guimarães TM. A relação médico-paciente e seus aspectos psicodinâmicos. Rev Bioética. 2003; 11: 101-12.

8. Beauchamp TL, Childress JF. Princípios de ética biomédica. São Paulo: Loyola; 2002.

9. Brasil. Conselho Federal de Medicina. Resolução CFM n ${ }^{\circ}$

Recebido em 19 de outubro de 2010

Versão final apresentada em 10 de novembro de 2010

Aprovado em 13 de dezembro de 2010 da autodeterminação do paciente, momentânea ou definitiva;

f) Torna-se necessário entender que a aplicação das ações beneficentes no atendimento clínico se processa dentro da relação médico-paciente;

g) Quanto melhor essa relação é construída, tanto melhor será a decisão médica que vai de não causar dano ao paciente até procedimentos de agir em seu benefício, respeitando sua autonomia;

h) Fica evidente, pois, que o médico conhecendo bem seu paciente deve agir ponderando sempre na linha de raciocínio de tanto quanto possível não causar dano ao paciente;

i) Julgamos que se compatibilizará melhor a beneficência e o paternalismo em uma relação de médio ou alto envolvimento, onde o médico mantenha sua autoridade, preservando seus conhecimentos e se responsabilizando pela tomada da decisão, e o paciente, por sua vez, também participe de acordo com seus valores morais e pessoais.

1.805/2006. Na fase terminal de enfermidades graves e incuráveis é permitido ao médico limitar ou suspender procedimentos e tratamentos que prolonguem a vida do doente, garantindo-lhe os cuidados necessários para aliviar os sintomas que levam ao sofrimento, na perspectiva de uma assistência integral, respeitada a vontade do paciente ou de seu representante legal. Brasília; 2006.

10. Brasil. Ministério Público. Seção Judiciária do Distrito Federal. Ação Civil Pública. Processo no 2007.34.00.014809-3. [on line]. [Acesso em $7 \mathrm{dez} 2010$ ]. Disponível em: http://www.df.trf1.gov.br/inteiro_teor/ doc inteiro teor/14vara/2007.34.00.014809-3 decisao 2310-2007.doc

11. Brasil. Conselho Federal de Medicina. Informativo jurídico CFM no 281/2010. [on line]. [Acesso em $7 \mathrm{dez} 2010$ ] Disponível em: http://www.portalmedico.org.br/include/ decisoes/mostra_decisao.asp?id=507

12. Brasil. Constituição Federal. Brasília: Senado Federal; 1988. 